DOI: 10.20472/IAC.2017.031.042

\title{
RANEEM SALEM
}

King Fahd medical City, Saudi Arabia

\section{MOVING FORWARD: NEAR PEER TEACHING EXPERIENCE OF UNDERGRADUATE MEDICAL STUDENTS}

\begin{abstract}
:
Abstract

Introduction Near Peer Teaching is a relatively novel and interesting experience and spreading across the world. Students who have experience peer teaching get an insight into their own abilities and often find it beneficial. Most studies have been performed in the west and there is paucity of data in our region.

Objectives To shed the light on peer teaching experience at our college and the perceptions of the students as well as the role of peer teachers in the process.

Methods Modified Clinical teaching preference Questionnaire (CTPQ) and Peer teaching experience questionnaire(PTEQ) were distributed to 1 st year $(n=34)$ and 6 th year students $(n=31)$ as learner group and to peer teachers(interns, $n=6$ and 6th yr students, $n=7$ ) at King Fahad Medical City, King Saud Bin Abdulaziz University for Health Sciences. These questionnaires address the teaching/learning peer teaching experience including the role of the peer teacher. Demographic data, age, gender, previous training and previous teaching/learning experience from peers were noted. The responded questionnaires were collected and anonymously analyzed, followed by statistical analysis.

Results The majority of near peer teachers and near peer learners who were at different levels and in different groups and rotations responded positively to peer teaching provided that the content was relevant. As for the role of peer teachers, both groups identified information provider and facilitator as more suitable roles than as a role model, planner, assessor and resource developer.

Conclusion Peer teaching can be a solution for medical schools that are facing increasing numbers of students and the shortage of efficient faculty members.
\end{abstract}

\section{Keywords:}

Peer; teach; interns; medical students; training; skills, education, new methods.

JEL Classification: 100 